\title{
The International Database of HOme blood pressure in relation to Cardiovascular Outcome (IDHOCO): moving from baseline characteristics to research perspectives
}

\author{
Teemu J Niiranen ${ }^{1,2}$, Lutgarde Thijs ${ }^{3}$, Kei Asayama, ${ }^{3,4}$, Jouni K Johansson ${ }^{1}$, Takayoshi Ohkubo ${ }^{4,5}$, \\ Masahiro Kikuya $^{4}$, José Boggia ${ }^{6}$, Atsushi Hozawa ${ }^{7}$, Edgardo Sandoya ${ }^{8}$, George S Stergiou ${ }^{9}$, Ichiro Tsuji ${ }^{10}$, \\ Antti M Jula ${ }^{1}$, Yutaka Imai ${ }^{4}$ and Jan A Staessen ${ }^{3,11}$, on behalf of the IDHOCO investigators ${ }^{12}$
}

The objective of this study is to construct an International Database of HOme blood pressure in relation to Cardiovascular Outcome (IDHOCO). The main goal of this database is to determine outcome-based diagnostic thresholds for the self-measured home blood pressure (BP). Secondary objectives include investigating the predictive value of white-coat and masked hypertension, morning and evening BP, BP and heart rate variability, and the home arterial stiffness index. We also aim to determine an optimal schedule for home BP measurements that provides the most accurate risk stratification. Eligible studies are population-based, have fatal as well as nonfatal outcomes available for analysis, comply with ethical standards, and have been previously published in peer-reviewed journals. In a meta-analysis based on individual subject data, composite and causespecific cardiovascular events will be related to various indexes derived by home BP measurement. The analyses will be stratified by a cohort and adjusted for the clinic BP and established cardiovascular risk factors. The database includes 6753 subjects from five cohorts recruited in Ohasama, Japan $(n=2777)$; Finland $(n=2075)$; Tsurugaya, Japan $(n=836)$; Didima, Greece $(n=665)$; and Montevideo, Uruguay $(n=400)$. In these five cohorts, during a total of 62106 person-years of follow-up (mean 9.2 years), 852 subjects died and 740 participants experienced a fatal or nonfatal cardiovascular event. IDHOCO provides a unique opportunity to investigate several hypotheses that could not reliably be studied in individual studies. The results of these analyses should be of help to clinicians involved in the management of patients with suspected or established hypertension.

Hypertension Research (2012) 35, 1072-1079; doi:10.1038/hr.2012.97; published online 5 July 2012

Keywords: BP measurement; epidemiology; home; self-measurement

\section{INTRODUCTION}

Hypertension, one of the most important challenges facing public healthcare worldwide, cannot be prevented, detected, treated, or controlled without accurate and practical methods for blood pressure (BP) measurement. ${ }^{1}$ Self-measurement of BP at home seems to offer specific advantages over conventional clinic measurement, as it allows for the identification of patients with white-coat, masked and sustained hypertension, with readings taken under standardized conditions, little measurement variability and good reproducibility. ${ }^{2}$ Home BP measurement is also a method appealing to most patients that can lead to better BP control by increasing awareness of hypertension, and adherence to and persistence of drug treatment. ${ }^{3,4}$ Furthermore, home BP seems to be closely associated with hypertensive end-organ damage than clinic BP, even for

${ }^{1}$ Department of Chronic Disease Prevention, Population Studies Unit, National Institute for Health and Welfare, Turku, Finland; ${ }^{2}$ Department of Medicine, Turku University Hospital, Turku, Finland; ${ }^{3}$ Department of Cardiovascular Sciences, The Studies Coordinating Centre, Division of Hypertension and Cardiovascular Rehabilitation, University of Leuven, Leuven, Belgium; ${ }^{4}$ Department of Planning for Drug Development and Clinical Evaluation, Tohoku University Graduate School of Pharmaceutical Sciences, Sendai, Japan; ${ }^{5}$ Department of Health Science, Shiga University of Medical Science, Otsu, Japan; ${ }^{6}$ The Centro de Nefrologiía and Departamento de Fisiopatologiía, Hospital de Cliínicas, Universidad de la Repuíblica, Montevideo, Uruguay; ${ }^{7}$ Department of Public Health, Yamagata University, Graduate School of Medicine, Yamagata, Japan; ${ }^{8}$ Department of Cardiology, Asociación Española Primera de Socorros Mutuos, Montevideo, Uruguay; ${ }^{9}$ Third Department of Medicine, Hypertension Center, University of Athens, Sotiria Hospital, Athens, Greece; ${ }^{10}$ Department of Public Health, Tohoku University Graduate School of Medicine, Sendai, Japan and ${ }^{11}$ Department of Epidemiology, Maastricht University, Maastricht, The Netherlands

12 Listed in the Appendix

Correspondence: Dr JA Staessen, Department of Cardiovascular Sciences, The Studies Coordinating Centre, Division of Hypertension and Cardiovascular Rehabilitation, University of Leuven, Campus Sint Rafaël, Kapucijnenvoer 35, Block d, PO Box 7001, BE, 3000 Leuven, Belgium.

E-mail: jan.staessen@med.kuleuven.be

Received 15 March 2012; revised 15 April 2012; accepted 26 April 2012; published online 5 July 2012 
a low number of measurements. ${ }^{5,6}$ More importantly, some studies, ${ }^{7-10}$ though not all, ${ }^{11,12}$ have suggested that home BP could have a stronger predictive power for future cardiovascular events than clinic BP.

In addition to its benefits, home BP measurement has become widely available for the general public owing to the introduction of small devices that are easily and reliably operated. Already in 2005, $64 \%$ of American hypertensive patients owned a home BP monitor. ${ }^{13}$ In contrast to ambulatory BP monitoring, self-measurement of BP is cheap and simple, with most of the advantages offered by ambulatory monitoring.

Despite the numerous advantages of home BP measurement, the diagnosis and treatment of hypertension are still mainly based on clinic BP values. One reason for this is that the outcome data on the prognostic significance of home BP has been limited and has provided somewhat equivocal results. ${ }^{7-12}$ In addition, the widespread clinical use of home BP measurement has been limited by the lack of a generally accepted reference frame and operational thresholds for initiating treatment, as the current recommendations on home BP measurement mainly rely on statistical parameters derived from cross-sectional analyses of reference populations instead of the outcome data. ${ }^{14-18}$

Collaborative meta-analyses of individual subject data constitute a powerful research tool to clarify the role of cardiovascular risk factors in relation to total and cause-specific mortality and morbidity, over and beyond the prognostic information generated by single cohort studies. ${ }^{1}$ Earlier quantitative overviews have already dramatically refined our understanding of the risk conferred by clinic and ambulatory BP. ${ }^{1,19}$ Furthermore, the currently recommended population-based thresholds for normal ambulatory BP have been determined in an outcome-driven meta-analysis of individual subject data. ${ }^{20}$ In contrast, the operational thresholds for self-measured home BP have been determined in cross-sectional meta-analyses, which have lacked a prospective dimension. ${ }^{16,21}$ As a result, both studies concluded that establishing an operational threshold for selfmeasured home BPs requires that the relationship between home measurements and the incidence of cardiovascular complications be clarified further by prospective studies. ${ }^{16,21}$

We therefore built a shared new resource of prospective studies conducted in the general population, with the objective of elucidating with great precision to what extent home BP improves risk stratification over and beyond clinic BP. We chose IDHOCO as the acronym for the new International Database of HOme blood pressure in relation to Cardiovascular Outcome.

\section{METHODS}

\section{Study eligibility}

Eligible studies are those performed in population samples. At least two baseline home and clinic BP measurements, and information on subsequent fatal and nonfatal outcomes should be available. Studies only qualify for inclusion in IDHOCO if they have been ethically approved, if at enrollment participants gave informed consent, and if they have been reported in peerreviewed journals.

\section{Identification of studies}

On the basis of our knowledge of the literature, we identified six large-scale studies, with self-measured home BP measurement with outcome data: the Ohasama study, ${ }^{8,10}$ the Finn-Home study, ${ }^{9}$ the Montevideo study, ${ }^{22}$ the Pressioni Arteriose Monitorate E Loro Associazioni study, ${ }^{12}$ the Tsurugaya study $^{23,24}$ and the Didima study. ${ }^{11}$ An electronic search of the literature performed in February 2012, using as search terms 'home BP', 'self-measured
BP' and 'population' did not reveal any other eligible study in a general population. We will repeat searches at 6-month intervals.

\section{Data collection}

The IDHOCO database is constructed and maintained at the Studies Coordinating Centre in Leuven, Belgium. Although respecting medical confidentiality and national legislations on the protection of privacy, investigators will provide information in electronic format on each participant's baseline characteristics, anthropometrics, background information on previous medical conditions and medications, clinic BP and home BP measurements. With regard to follow-up, the information to be computerized includes duration of follow-up, vital status at the end of follow-up, and the incidence of fatal and nonfatal events.

After integration of the participants' information into the database, each investigator will receive detailed summary statistics of his cohort. This process should help to ensure that the common database incorporates correct information, and that there will be no conflicts between data to be used in the meta-analysis and those already reported by individual investigators in the literature. The IDHOCO database will be held in strict confidence and will not be used in any publication without the permission of an investigator who has contributed data to a given analysis.

The clinic BP should be measured by a standard mercury sphygmomanometer or a validated automated device using the appropriate cuff size. The average of the first two clinic BP readings obtained in the sitting or supine position will be used for analysis. The thresholds proposed by American Heart Association Council on High Blood Pressure Research ${ }^{14}$ and the European Societies of Hypertension ${ }^{25}$ will be used for the classification of participants according to their clinic and home BP. Patients on BP-lowering drugs will be classified as hypertensive, irrespective of the measured BP.

Home BP should be measured with a validated, automated device, using the appropriate cuff size. Home BP measurements should be unedited. The monitors should have been validated according to the European Society of Hypertension, ${ }^{26}$ British Hypertension Society ${ }^{27}$ or the Association for the Advancement of Medical Instrumentation ${ }^{28}$ guidelines. At the Studies Coordinating Centre, the same SAS macro will process all individual home BP measurements. Editing will be limited to deleting those with a systolic BP lower than or equal to the diastolic BP. Subjects with only one home or clinic measurement will not be considered for analysis.

\section{Other measurements}

Data transfer will include detailed information on each subject's medical history, smoking and drinking habits, and intake of medications. Body mass index will be calculated as body weight in kilograms divided by height in meters squared. Diabetes mellitus will be defined as a self-reported diagnosis, a fasting or random blood glucose level of at least 7.0 to $11.1 \mathrm{mmoll}^{-1}$, respectively, or the use of antidiabetic drugs. Previous cardiovascular disease includes cardiac, cerebrovascular and peripheral vascular disorders.

\section{Definition of primary and secondary outcomes}

The primary analysis will be performed for a composite cardiovascular endpoint, including cardiovascular mortality, nonfatal myocardial infarction, surgical and percutaneous coronary revascularization, heart failure, pacemaker implantation and stroke. If a subject experienced more than one cardiovascular event, only the first will be considered for analysis. Secondary analyses will be conducted on the following outcomes: (i) all-cause mortality; (ii) cardiovascular mortality; (iii) noncardiovascular mortality; (iv) cerebrovascular events (fatal and nonfatal stroke); (v) coronary events (mortality from ischemic heart disease and sudden death, nonfatal myocardial infarction and coronary revascularization); (vi) cardiac events (coronary events, fatal and nonfatal heart failure, pacemaker implantation and other cardiac deaths).

The events will be classified according to the ICD-10 (International Statistical Classification of Diseases, 10th Revision) code associated with the event. In case the ICD codes are not available in the transferred data, the definition of events as given by the investigators will be accepted with reference to the publication on each cohort in the peer-reviewed literature. 


\section{Analyses}

For database management and statistical analysis, SAS software version 9.3 (SAS Institute, Cary, NC, USA) will be used.

In exploratory analyses, incidence rates per 1000 subject years will be plotted by quantiles of the home systolic and diastolic BPs, whereas standardizing by the direct method for cohort, sex and age ( $<40,40$ to 60 , and $\geqslant 60$ years). The number of quantiles will depend on the number of events available for analysis.

Next, the association between the outcome and home BP will be assessed using the Cox proportional hazards model. Both unadjusted and adjusted analyses will be performed. Adjusted analyses will include the following covariables: cohort, sex, age, body mass index, smoking habits, serum total cholesterol, diabetes mellitus, treatment with antihypertensive drugs and history of cardiovascular disease at enrollment. Possible missing continuous covariables will be interpolated from the regression slope on age after stratification for cohort and sex. Missing categorical covariates will be replaced with a design variable to the cohort-specific and sex-specific mean of the codes $(0,1)$. Adjustment for cohort will be made through the use of a stratified Cox model or by introduction of design variables in the Cox models. Sensitivity analyses will be performed in untreated subjects, in subjects below and above 50 years of age, and in subjects with and without a previous history of cardiovascular disease. In addition, sensitivity analyses will always be conducted excluding one cohort at a time. This should confirm that results are consistent across cohorts and are not being driven by a single population.

Diagnostic thresholds for the self-measured home BP will be obtained in five steps. First, the 10-year absolute risk of cardiovascular endpoints associated with various thresholds on clinic BP measurement will be calculated from a Cox model, with the clinic BP entered as a continuous covariate. Second, 10year incidence rates of cardiovascular endpoints associated with home BP levels ranging from the 5th to the 95th percentiles, using intervals of $0.1 \mathrm{~mm} \mathrm{Hg}$ will be computed. In a third step, the home BP levels that are associated with the same cardiovascular risk as the clinic BP thresholds will be selected. Next, the bootstrap distribution of the so-obtained diagnostic thresholds for the home $\mathrm{BP}$ will be calculated by randomly resampling the study population 1000 times with replacement, using the PROC SURVEYSELECT procedure, as implemented in the SAS package. For each new sample, the first three steps will be repeated. The TIES_EXACT option in the PROC PHREG procedure will be used to account for tied event times caused by the re-sampling procedure. Finally, the bootstrap point estimates and $95 \%$ confidence intervals of the home BP thresholds will be used to suggest cut-off limits for various levels of the self-measured BP at home. ${ }^{29}$

\section{Research objectives}

Outcome-driven diagnostic thresholds for home BP. Although BP is continuously distributed, clinicians need a diagnostic reference frame to interpret home BP values and to classify patients. Current guidelines propose operational thresholds for home $\mathrm{BP}$, but these limits rely mainly on the distribution of the home BP in normotensive reference populations or on the regression of home on clinic BP. ${ }^{14,15}$ Generating outcome-driven diagnostic thresholds for home BP is the major objective of the IDHOCO research consortium.

The relation between cardiovascular outcomes and $\mathrm{BP}$, irrespective of the technique of measurement, is usually considered to be log-linear and continuous. ${ }^{1}$ Nevertheless, we chose to adhere to the general consensus in the current guidelines and plan to determine the levels of the home BP that yield risks equivalent to those associated with optimal and normal $\mathrm{BP}$, and hypertension in clinic measurements. ${ }^{14,25}$ As an alternative approach, we will also calculate the levels of the home BP resulting in a 5 or $10 \%$ overall cardiovascular risk over 10 years. The latter procedure does not involve any assumption of risk associated with clinic BP.

Home BP measurement to refine risk stratification. In clinical practice, home $\mathrm{BP}$ measurement is used to refine risk stratification. Along this line, IDHOCO will constitute a powerful resource to address several issues related to the prognostic significance of home BP. The preliminary list of home BP indexes, of which the predictive value will be investigated, includes the following: (i) white-coat and masked hypertension; (ii) the BP levels during morning and evening, and their ratio; (iii) measures of home-measured BP and heart rate variability, (iv) the home heart rate; and (v) pulse pressure and the home arterial stiffness index. In addition, we will investigate to what extent diabetes mellitus or a history of cardiovascular disease, as compared with the absence of these conditions, impacts on the prognostic accuracy of the home BP. We will also try to determine the optimum number of BP self-measurements to be taken at home requested for an accurate prediction of cardiovascular risk. All aforementioned analyses will explore whether the indexes derived from home measurement are predictive over and above those derived from clinic BP readings. Results from analyses, which require a dichotomization of the study population, such as those of white-coat and masked hypertension, will be confirmed by analyses that include the exposure variables as continuous measurements. It is also our intention to construct risk charts similar to those implemented in the NIPPON DATA $80,{ }^{30}$ Framingham ${ }^{31}$ or SCORE ${ }^{32}$ systems, but including home BP as an additional risk factor.

\section{RESULTS}

Of the six existing studies, we excluded one, because follow-up did not include nonfatal events. ${ }^{12}$ After contacting the investigators of the five eligible studies representing two Asian, one South American and two European cohorts, all were willing to participate in the IDHOCO database and had outcome data available. These cohorts were recruited by inviting (i) the whole adult ${ }^{8,10,11}$ or elderly ${ }^{23,24}$ population of a single community; (ii) a random nation-wide sample aged 44-74 years drawn from the population register; ${ }^{9}$ or (iii) a random city-wide adult sample drawn from individuals registered in a nonprofit mutual medical scheme, ${ }^{22}$ to take part in the respective studies.

Currently, the IDHOCO database includes 6753 subjects: 2777 residents of Ohasama, Japan; ${ }^{8,10}$ a nation-wide population sample of 2075 residents of Finland $; 9836$ residents of Tsurugaya district, Sendai, Japan; ${ }^{23,24} 665$ residents of Didima, Greece; ${ }^{11}$ and 400 inhabitants of Montevideo, Uruguay. ${ }^{22}$ Table 1 lists the characteristics of these subjects by cohort. Overall, these five cohorts include 3806 women (56\%), 1444 smokers (21\%), 554 diabetic patients (8\%) and 566 participants with previous history of cardiovascular disease $(8 \%)$. Mean age (5th to 95th percentile interval) was 59.1 years (36.2-79.8). Of the 3093 hypertensive patients (46\%), 1465 (47\%) were taking BP-lowering drugs.

The clinic BPs were obtained at an examination center, and were measured with a mercury sphygmomanometer ${ }^{9,11}$ or a validated automatic monitor ${ }^{33,34}$ after a 2 - or 5-min rest in the sitting position. In the Tsurugaya cohort, clinic BP was measured in the supine position after a 2 -min rest during pulse-wave velocity measurement ${ }^{35}$ (Table 2). Less than two clinic BP measurements were available in 267 subjects. Mean values in the remaining 6486 subjects were $134.0 \pm 20.5 \mathrm{~mm} \mathrm{Hg}$ systolic and $79.0 \pm 11.8 \mathrm{~mm} \mathrm{Hg}$ diastolic (Table 1). The home BP measurements were obtained at the subjects' homes after a 2-5-min rest with a validated, ${ }^{33,36-38}$ oscillometric device in the sitting position (Table 2). Less than two home BP readings were available in 18 subjects. The mean home systolic and diastolic BPs in the remaining 6735 subjects averaged $127.0 \pm 18.1 \mathrm{~mm}$ $\mathrm{Hg}$ for systolic and $76.1 \pm 10.0 \mathrm{~mm} \mathrm{Hg}$ for diastolic (Table 1). Two subjects had less than two clinic and less than two home BP measurements available. The clinic and home BPs in the 6470 subjects with more than one home and clinic measurement are depicted by sex and age in Figure 1. In this cohort, data on total serum cholesterol and body mass index was missing in 133 (118 from Ohasama) and 382 (353 from Ohasama) subjects, respectively.

The ascertainment and definition of events in the cohorts has been previously described in more detail and is summarized in Table 3. ${ }^{8-11,22,24}$ Table 4 shows the number of events in each cohort currently included in the database. Mean follow-up time was 9.2 years 
Table 1 Baseline characteristics

\begin{tabular}{|c|c|c|c|c|c|c|}
\hline Characteristic & Ohasama & Finn-Home & Tsurugaya & Didima & Montevideo & Five cohorts \\
\hline Subjects, no & 2777 & 2075 & 836 & 665 & 400 & 6753 \\
\hline Age (years) & $59.2(12.7)$ & $57.1(8.5)$ & $75.3(4.6)$ & $54.3(17.6)$ & $41.9(12.7)$ & $59.1(13.6)$ \\
\hline Body mass index $\left(\mathrm{kg} \mathrm{m}^{-2}\right)$ & $23.5(3.1)$ & $27.4(4.5)$ & $23.9(3.4)$ & $27.1(4.3)$ & $26.0(4.5)$ & $25.3(4.3)$ \\
\hline Weight (kg) & $55.9(9.7)$ & $77.4(15.0)$ & $57.1(9.6)$ & $71.5(12.0)$ & $73.0(15.3)$ & $65.6(15.7)$ \\
\hline$<2$ clinic measurements, no (\%) & $257(9)$ & 0 & $10(1)$ & 0 & 0 & $267(4)$ \\
\hline \multicolumn{7}{|l|}{ Blood pressure $(\mathrm{mm} \mathrm{Hg})$} \\
\hline Office systolic & $131.3(18.1)$ & $137.4(20.3)$ & $145.4(20.6)$ & $127.3(21.4)$ & $120.1(19.5)$ & $134.0(20.5)$ \\
\hline Office diastolic & $74.6(11.3)$ & $83.7(10.6)$ & $83.5(10.7)$ & $76.4(11.0)$ & $77.7(11.7)$ & $79.0(11.8)$ \\
\hline Home systolic & $123.4(14.5)$ & $129.9(18.7)$ & $140.3(19.9)$ & $124.3(19.8)$ & $114.8(14.1)$ & $127.1(18.2)$ \\
\hline \multicolumn{7}{|l|}{ Pulse rate (beats per $\mathrm{min}$ ) } \\
\hline Home & $68.5(7.5)$ & $68.4(9.2)$ & $65.6(8.9)$ & $74.5(8.7)$ & $76.3(12.3)$ & $69.2(9.1)$ \\
\hline Serum cholesterol $\left(\mathrm{mmoll}^{-1}\right)$ & $5.0(0.9)$ & $6.1(1.1)$ & $5.3(0.9)$ & $5.1(0.4)$ & $5.5(1.0)$ & $5.5(1.1)$ \\
\hline Smokers, no (\%) & $587(21)$ & $482(23)$ & $102(12)$ & $169(26)$ & $104(26)$ & $1444(21)$ \\
\hline Diabetes mellitus, no (\%) & $252(9)$ & $130(6)$ & $124(15)$ & $30(5)$ & $18(5)$ & $554(8)$ \\
\hline Cardiovascular disease, no (\%) & $90(3)$ & $251(12)$ & $132(16)$ & $59(9)$ & $34(9)$ & $566(8)$ \\
\hline Antihypertensive treatment, no (\%) & $510(18)$ & $470(23)$ & $348(42)$ & $94(14)$ & $43(11)$ & $1465(22)$ \\
\hline Hypertension, no (\%) & 1017 (37) & $1146(55)$ & $609(73)$ & $232(35)$ & $89(22)$ & $3093(46)$ \\
\hline
\end{tabular}

Abbreviation: n.a., not available.

Data are mean (s.d.) or number of patients (\%). Home blood pressure is the mean of all available readings.

Table 2 Information on blood pressure measurements

\begin{tabular}{|c|c|c|c|c|c|c|c|c|c|}
\hline Study & $\begin{array}{c}\text { Device } \\
\text { type }\end{array}$ & Device used & $\begin{array}{l}\text { No. of } \\
\text { days }\end{array}$ & $\begin{array}{c}\text { Times per } \\
\text { day }\end{array}$ & $\begin{array}{l}\text { Repeat } \\
\text { readings }\end{array}$ & Measurer & Position & $\begin{array}{l}\text { Mean no. of } \\
\text { readings }\end{array}$ & $\begin{array}{c}\text { Min. rest before/between } \\
\text { readings }\end{array}$ \\
\hline \multicolumn{10}{|l|}{ Clinic } \\
\hline Ohasama & $A A$ & USM-700 F 34 & 1 & 1 & 2 & $\mathrm{~N} / \mathrm{T}$ & $\mathrm{SI}$ & 1.8 & $2 / 0$ \\
\hline Finn-Home & MM & Mercuro 300 & 1 & 1 & 2 & $\mathrm{~N}$ & SI & 2.0 & $5 / 2$ \\
\hline Tsurugaya & $\mathrm{AO}$ & FORM ABI/PWV 35 & 1 & 1 & $\begin{array}{c}2 \\
\text { simultaneous }\end{array}$ & $\mathrm{T}$ & SU & 2.0 & $2 /-$ \\
\hline Didima & $\mathrm{MM}$ & Baumomanometer & 2 & 1 & 3 & $P$ & SI & 6.0 & $5 / 1$ \\
\hline Montevideo & $\mathrm{AO}$ & Omron HEM-705CP33 & 1 & 1 & 3 & $N / P$ & $\mathrm{SI}$ & 3.0 & $5 / 2$ \\
\hline \multicolumn{10}{|l|}{ Home } \\
\hline Ohasama & SAO & Omron HEM-401C 36 & 4 weeks & $2(M, E)$ & 1 & S & SI & 45.9 & $2 /-$ \\
\hline Finn-Home & $\mathrm{AO}$ & Omron HEM-722C 37 & 7 & $2(M, E)$ & 2 & S & SI & 26.6 & $5 / 2$ \\
\hline Tsurugaya & $\mathrm{AO}$ & Omron HEM-74737,a & 1 month & $1(\mathrm{M})$ & 1 & S & $\mathrm{SI}$ & 15.0 & $5 /-$ \\
\hline Didima & $\mathrm{AO}$ & Omron HEM-705CP33 & 3 & $2(M, E)$ & 2 & $\begin{array}{l}\mathrm{S}-83 \% \\
\mathrm{R}-17 \%\end{array}$ & $\mathrm{SI}$ & 11.8 & $5 / 1$ \\
\hline Montevideo & $\mathrm{AO}$ & SpaceLabs $90207^{38}$ & 1 & $2(M, E)$ & 1 & S & SI & 2.0 & $5 /-$ \\
\hline
\end{tabular}

Abbreviations: $\mathrm{AA}$, automatic auscultatory; $\mathrm{AO}$, automatic oscillometric; $\mathrm{E}$, evening; $\mathrm{M}$, morning; $\mathrm{MM}$, mercury manometer; N, nurse; $\mathrm{P}$, physician; R, relative; $\mathrm{S}$, subject; SAO, semi-automatic oscillometric; SI, sitting; SU, supine; T, technician.

Superscript number refers to validation study.

asame device as HEM-735C, except that it does not incorporate an integrated circuit memory.

(median 8.3 years, 5th to 95th percentile interval, $4.1-16.8$ years) and ranged from 5.2 years (median 5.5 years, 5th to 95th percentile interval, 2.3-5.6 years) in Tsurugaya to 11.8 years (median 11.9 years, 5 th to 95 th percentile interval $3.5-16.9$ years) in Ohasama. In the overall study population, during a total of 62106 person-years of follow-up, 852 subjects died and 740 participants experienced a fatal or nonfatal cardiovascular event. The unadjusted incidence of fatal and nonfatal cardiovascular events averaged 12.3 events per thousand 
person-years, ranging from 5.0 to 16.8 events per thousand personyears in Montevideo and Tsurugaya, respectively.

\section{DISCUSSION}

From 2006 onwards, the International Database of Ambulatory BP in relation to Cardiovascular Outcome (IDACO) has been constructed and maintained with the objective to define outcome-based diagnostic thresholds for the ambulatory BP. ${ }^{20,39}$ Along similar lines, the objective of the present IDHOCO project is to construct an international population-based database, using individual subject data with the objective to give clinicians a diagnostic reference frame to interpret self-measured home BP values and to classify patients.

Clinicians need guidance about efficient diagnostic strategies and evidence-based medicine clearly includes evidence-based operational thresholds. Systematic reviews and accompanying meta-analyses are the cornerstones of evidence-based medicine. Conventional systematic reviews and meta-analyses, however, rely on aggregated information.

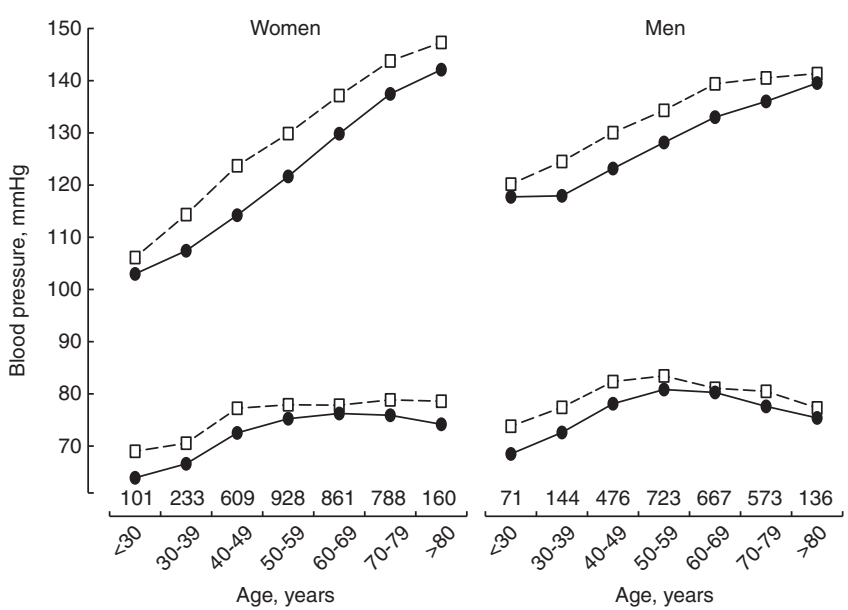

Figure 1 Clinic (open squares on dotted lines) and home (closed circles on solid line) systolic and diastolic BPs by sex and age. This analysis included only subjects with two valid home and clinic measurements $(n=6470)$. Home BP is the mean of all available readings. Numbers indicate the number of subjects in each category.
As there is no access to data other than those reported by the original authors, these meta-analyses are restricted by the analyses performed in the original studies, making it impossible to perform more detailed analyses. An individual subject meta-analysis allows the use of the same statistical approach and quality standards across studies, and the heterogeneity between cohorts can be better assessed. Although a meta-analysis using individual subject data can be time consuming due to efforts required for data acquisition, extraction and merging, we decided that this was the best possible approach for reaching our study objectives.

We opted not to mix cohorts of hypertensive patients and random population samples in our meta-analysis as the main purpose of the IDHOCO project is to determine diagnostic thresholds for the general population. We believe that the external validity and generalizability of population-based results are larger than those emerging from cohorts of selected hypertensive patients, especially when the large sample size of IDHOCO enables subgroup analyses of, for example, subjects with and without diabetes, antihypertensive treatment, or previous history of cardiovascular disease. Furthermore, in hypertensive patients, BP-lowering treatment can be a confounder with too large an impact to adjust for. Indeed, in the patients randomized to placebo in the Systolic Hypertension in Europe trial, systolic BP predicted the incidence of cardiovascular complications. In contrast, in the active-treatment group, systolic BP at entry did not significantly predict cardiovascular endpoints, regardless of the technique of $\mathrm{BP}$ measurement. ${ }^{40}$ In the five cohorts currently included in the database, only one-fifth of the patients were on antihypertensive drug treatment at baseline. All analyses will be adjusted for antihypertensive drug treatment. In addition, a sensitivity analysis in untreated subjects is planned to show whether or not the results are confounded by antihypertensive drug treatment.

We hope that IDHOCO will, like its sister study IDACO, ${ }^{39}$ provide investigators the opportunity to investigate several hypotheses that could not be reliably studied from smaller individual cohorts. For instance, the current guidelines on home BP measurement make equivocal recommendations for the optimal schedule of home BP measurement. ${ }^{14,15,17}$ We plan to assess how the number and timing (morning $v s$. evening) of measurements affects the prognostic value of self-measured BP, so that definite instructions can be given to patients on how and when to measure their home BP. It should also be possible to assess in this project how antihypertensive medication and

Table 3 Ascertainment of events

\begin{tabular}{|c|c|c|c|c|c|}
\hline Event & Ohasama ${ }^{10}$ & Finn-Home ${ }^{9}$ & Tsurugaya24 & Didima $^{11}$ & Montevideo 22 \\
\hline \multicolumn{6}{|c|}{ Ascertainment of events } \\
\hline Fatal & Death certificates & Death certificates & $\begin{array}{l}\mathrm{NHI} \text { database, } \\
\text { medical records }\end{array}$ & Death certificates & Death certificates \\
\hline Nonfatal & $\begin{array}{l}\text { Stroke registration system, } \\
\text { medical records }\end{array}$ & $\begin{array}{l}\text { Hospital discharge } \\
\text { register }\end{array}$ & $\begin{array}{l}\mathrm{NHI} \text { database, } \\
\text { medical records }\end{array}$ & $\begin{array}{l}\text { Interviews, } \\
\text { medical records }\end{array}$ & $\begin{array}{c}\text { Interviews, } \\
\text { medical records }\end{array}$ \\
\hline
\end{tabular}

ICD-10 codes, if available

Stroke

Sudden death

Heart failure

Peripheral arterial disease

Ischemic heart disease

Other cardiac death
I60-164

146 and R96

150 and $\mathrm{J} 81$

170-174

$121-125$

105, I11, 134-135, 138, 144,

147-149, 199

\author{
161 and 163 \\ 146 and R96 \\ 150 \\ 170-174 \\ 121-125
}

111
$160-64$

146 and R96

150

170-74

121-125
Investigator-defined

Investigator-defined

Investigator-defined

Investigator-defined

Investigator-defined

Investigator-defined
Investigator-defined Investigator-defined Investigator-defined Investigator-defined Investigator-defined Investigator-defined 
Table 4 Incidence of events per cohort

\begin{tabular}{|c|c|c|c|c|c|c|}
\hline Statistic & Ohasama & Finn-Home & Tsurugaya & Didima & Montevideo & Five cohorts \\
\hline Number of subjects & 2777 & 2075 & 836 & 665 & 400 & 6753 \\
\hline Mean follow-up & $11.8(4.0)$ & $7.9(1.1)$ & $5.2(1.0)$ & $7.8(1.3)$ & $8.7(1.5)$ & $9.2(3.3)$ \\
\hline Total person-years & 32696 & 16431 & 4343 & 5164 & 3472 & 62106 \\
\hline \multicolumn{7}{|l|}{ Fatal events } \\
\hline All & 551 & 143 & 77 & 72 & 9 & 852 \\
\hline Noncardiovascular & 349 & 100 & 51 & 31 & 5 & 536 \\
\hline Unknown cause & 1 & 0 & 3 & 1 & 0 & 5 \\
\hline Cardiovascular & 201 & 43 & 23 & 40 & 4 & 311 \\
\hline Stroke & 102 & 6 & 5 & 5 & 3 & 121 \\
\hline Ischemic heart disease & 46 & 30 & 9 & 9 & 0 & 94 \\
\hline Sudden death & 7 & 1 & 2 & 15 & 0 & 25 \\
\hline Heart failure & 24 & $0^{a}$ & 4 & 11 & 1 & 40 \\
\hline Peripheral arterial disease & 6 & 3 & 3 & 0 & 0 & 12 \\
\hline Other cardiac death ${ }^{\mathrm{b}}$ & 16 & 3 & 0 & 0 & 0 & 19 \\
\hline \multicolumn{7}{|l|}{ Nonfatal events } \\
\hline Stroke & 227 & 45 & 44 & 8 & 2 & 326 \\
\hline Myocardial infarction & n.a. & 52 & 18 & 6 & 2 & n.a. \\
\hline Coronary revascularization & n.a. & 90 & n.a. & 3 & 8 & n.a. \\
\hline Heart failure & n.a. & 42 & n.a. & 2 & 3 & n.a. \\
\hline Pacemaker implantation & n.a. & n.a. & n.a. & 3 & n.a. & n.a. \\
\hline \multicolumn{7}{|l|}{ Fatal and nonfatal events } \\
\hline All cardiovascularc & 384 & 207 & 71 & 61 & 17 & 740 \\
\hline Cardiac events $^{d}$ & 93 & 167 & 27 & 48 & 12 & 347 \\
\hline Coronary events $\mathrm{e}$ & 53 & 137 & 24 & 32 & 9 & 255 \\
\hline Cerebrovascular events ${ }^{f}$ & 300 & 45 & 46 & 13 & 5 & 409 \\
\hline
\end{tabular}

Abbreviation: n.a., not available.

a Heart failure deaths in Finland are classified according to the cause underlying heart failure.

Includes valvular disease $(n=11)$, hypertensive heart disease $(n=6)$, endocarditis $(n=1)$ and 'unspecified disorder of circulatory system' $(n=1)$

${ }^{c}$ Cardiovascular mortality plus stroke and cardiac events.

${ }^{d}$ Coronary events, fatal and nonfatal heart failure, pacemaker implantation and other cardiac deaths.

eMortality from ischemic heart disease and sudden death, and incidence of myocardial infarction and coronary revascularization.

fFatal and nonfatal strokes. Composite events do not add up since they include only the first event.

medication subtypes affect morning and evening BP, and their relation to outcome. The clinical significance of masked and white-coat hypertension is also still somewhat controversial. ${ }^{41} \mathrm{We}$ hope to determine whether masked or white-coat hypertension are independent predictors of cardiovascular risk or whether home BP itself, along with other traditional risk factors, may be enough to stratify cardiovascular risk. One topic that needs further clarification as well is the prognostic significance of the variability in homemeasured BP and heart rate, as preliminary data show that both could be independent predictors of cardiovascular events. ${ }^{42,43}$

Despite all advantages, the future results of IDHOCO project must be interpreted within the context of their potential limitations. First, the anthropometric characteristics and the time of recruitment differed between cohorts. Second, the clinic and home BP measurements were not standardized in terms of device type, number of maximum measurements and intervals between readings. Third, the availability of endpoint data differed between cohorts. Fourth, information on serum cholesterol levels was not available for the Didima population. However, we will extrapolate total cholesterol values for the Didima population by sex and 10-year age strata from data provided by the ATTICA study investigators from a large population cohort examined in the same time period and in the same geographical area as the Didima cohort. ${ }^{44}$
Both in the United States and in Europe, home BP measurement is now recommended for almost all patients with hypertension. ${ }^{13,15}$ Despite this, fundamental questions regarding this method remain unanswered. We hope that IDHOCO will provide a unique opportunity to investigate several hypotheses that could not reliably be studied from individual studies. The results of these analyses should inform guidelines and be of help to clinicians involved in the management of patients with suspected or established hypertension.

\section{CONFLICT OF INTEREST}

The authors declare no conflict of interest.

\section{ACKNOWLEDGEMENTS}

We acknowledge the help of Associate Professor Demosthenes B Panagiotakos and the ATTICA study organization for providing the age- and sex-stratified cholesterol values for the Greek population. The European Union (Grants IC15-CT98-0329-EPOGH, LSHM-CT-2006-037093-InGenious HyperCare, HEALTH-2007-2.1.1-2-HyperGenes, HEALTH-2011.2.4.2-2-EU-MASCARA and the European Research Council Advanced Researcher Grant-2011-294713EPLORE), the Fonds voor Wetenschappelijk Onderzoek Vlaanderen, Brussels, Belgium (Grants G.0575.06 and G.0734.09) and the Katholieke Universiteit Leuven, Leuven, Belgium (Grants OT/04/34 and OT/05/49) gave support to the Studies Coordinating Center. The Ohasama study was supported in part by Grants for Scientific Research (18390192, 18590587, 19590929, 19790423, 
20590629, 21390201, 21591016, 22590767, 22790556, 22890017, 23249036 and 23790242) from the Ministry of Education, Culture, Sports, Science, and Technology, Japan; Grant-in-Aid (H18-Junkankitou (Seishuu)-Ippan-012, H20-Junkankitou (Seishuu)-Ippan-009, 013 and H23-Junkankitou (Seishuu)Ippan-005) from the Ministry of Health, Labor and Welfare, Health and Labor Sciences Research Grants, Japan; Grant-in-Aid for Japan Society for the Promotion of Science (JSPS) fellows (18.54042, 19.7152, 20.7198, 20.7477 and 20.54043); Health Science Research Grants and Medical Technology Evaluation Research Grants from the Ministry of Health, Labor and Welfare, Japan; Japan Arteriosclerosis Prevention Fund; Biomedical Innovation Grants; a Grant from the Miso Central Institute, Tokyo, Japan; and a Grant from the Sendai Knowledge Cluster Initiative, Sendai, Japan. The Finn-Home project organization created for the study involved the Finnish Center for Pensions, the Social Insurance Institution, the National Public Health Institute, the Local Government Pensions Institution, the National Research and Development Center for Welfare and Health, the Finnish Dental Society and the Finnish Dental Association, Statistics Finland, the Finnish Work Environment Fund, the Finnish Institute for Occupational Health, the UKK Institute for Health Promotion, the State Pensions Office and the State Work Environment Fund. The Asociacioín Espanñola Primera de Socorros Mutuos, The Agencia Nacional de Investigacioín e Innovacioín, the Comisioín Sectorial de Investigacioín Cientiífica and the Programa para la Formacioín y Fortalecimiento de los Recursos Humanos de los Prestadores Públicos de Servicios de Salud supported the Montevideo study. The Tsurugaya study was supported by a Health Sciences Research Grant for Health Service (H21-Choju-Ippan-001) from the Ministry of Health, Labor and Welfare, Japan, and the Japan Arteriosclerosis Prevention Fund.

1 Lewington S, Clarke R, Qizilbash N, Peto R, Collins R. Age-specific relevance of usual blood pressure to vascular mortality: a meta-analysis of individual data for one million adults in 61 prospective studies. Lancet 2002; 360: 1903-1913.

2 Ragot S, Genes N, Vaur L, Herpin D. Comparison of three blood pressure measurement methods for the evaluation of two antihypertensive drugs: feasibility, agreement, and reproducibility of blood pressure response. Am J Hypertens 2000; 13: 632-639.

3 Little P, Barnett J, Barnsley L, Marjoram J, Fitzgerald-Barron A, Mant D. Comparison of acceptability of and preferences for different methods of measuring blood pressure in primary care. BMJ 2002; 325: 258-259.

4 Agarwal R, Bills JE, Hecht TJ, Light RP. Role of home blood pressure monitoring in overcoming therapeutic inertia and improving hypertension control: a systematic review and meta-analysis. Hypertension 2011; 57: 29-38.

5 Niiranen T, Jula A, Kantola I, Moilanen L, Kahonen M, Kesaniemi YA, Nieminen MS, Reunanen A. Home-measured blood pressure is more strongly associated with atherosclerosis than clinic blood pressure: the Finn-HOME Study. J Hypertens 2007 25: 1225-1231.

6 Stergiou GS, Argyraki KK, Moyssakis I, Mastorantonakis SE, Achimastos AD, Karamanos VG, Roussias LG. Home blood pressure is as reliable as ambulatory blood pressure in predicting target-organ damage in hypertension. Am J Hypertens 2007; 20: 616-621.

7 Bobrie G, Chatellier G, Genes N, Clerson P, Vaur L, Vaisse B, Menard J, Mallion JM Cardiovascular prognosis of "masked hypertension" detected by blood pressure self-measurement in elderly treated hypertensive patients. JAMA 2004; 291: 1342-1349.

8 Asayama K, Ohkubo T, Kikuya M, Metoki H, Hoshi H, Hashimoto J, Totsune K, Satoh H, Imai Y. Prediction of stroke by self-measurement of blood pressure at home versus casual screening blood pressure measurement in relation to the Joint National Committee 7 classification - The Ohasama study. Stroke 2004; 35: 2356-2361.

9 Niiranen TJ, Hänninen MR, Johansson J, Reunanen A, Jula AM. Home-measured blood pressire is a stronger predictor of cardiovascular risk than office blood pressure. Hypertension 2010; 55: 1346-1350.

10 Ohkubo T, Imai Y, Tsuji I, Nagai K, Kato J, Kikuchi N, Nishiyama A, Aihara A, Sekino M, Kikuya M, Ito S, Satoh H, Hisamichi S. Home blood pressure measurement has a stronger predictive power for mortality than does screening blood pressure measurement: a population-based observation in Ohasama, Japan. J Hypertens 1998; 16 971-975.

11 Stergiou GS, Baibas NM, Kalogeropoulos PG. Cardiovascular risk prediction based on home blood pressure measurement: the Didima study. J Hypertens 2007; 25: 1590-1596.

12 Sega R, Facchetti R, Bombelli M, Cesana G, Corrao G, Grassi G, Mancia G. Prognostic value of ambulatory and home blood pressures compared with office blood pressure in the general population - Follow-up results from the Pressioni Arteriose Monitorate e Loro Associazioni (PAMELA) study. Circulation 2005; 111: 1777-1783.

13 Pickering TG, Miller NH, Ogedegbe G, Krakoff LR, Artinian NT, Goff D. Call to action on use and reimbursement for home blood pressure monitoring: a joint scientific statement from the American Heart Association, American Society Of Hypertension, and Preventive Cardiovascular Nurses Association. Hypertension 2008; 52: 10-29.

14 Pickering TG, Hall JE, Appel LJ, Falkner BE, Graves J, Hill MN, Jones DW, Kurtz T, Sheps SG, Roccella EJ. Recommendations for blood pressure measurement in humans and experimental animals: part 1: blood pressure measurement in humans: a statement for professionals from the Subcommittee of Professional and Public Education of the American Heart Association Council on High Blood Pressure Research. Hypertension 2005; 45: 142-161.

15 Parati G, Stergiou GS, Asmar R, Bilo G, de Leeuw P, Imai Y, Kario K, Lurbe E, Manolis A, Mengden T, O'Brien E, Ohkubo T, Padfield P, Palatini P, Pickering T, Redon J, Revera M, Ruilope LM, Shennan A, Staessen JA, Tisler A, Waeber B, Zanchetti A, Mancia G. ESH Working Group on Blood Pressure Monitoring. European Society of Hypertension guidelines for blood pressure monitoring at home a summary report of the Second International Consensus Conference on Home Blood Pressure Monitoring. J Hypertens 2008; 26: 1505-1526.

16 Thijs L, Staessen JA, Celis H, de Gaudemaris R, Imai Y, Julius S, Fagard R. Reference values for self-recorded blood pressure: a meta-analysis of summary data. Arch Intern Med 1998; 158: 481-488

17 Parati G, Stergiou G. Self blood pressure measurement at home: how many times? J Hypertens 2004; 22: 1075-1079.

18 Tsuji I, Imai Y, Nagai K, Ohkubo T, Watanabe N, Minami N, Itoh O, Bando T, Sakuma M, Fukao A, Satoh H, Hisamichi S, Abe K. Proposal of reference values for home blood pressure measurement: prognostic criteria based on a prospective observation of the general population in Ohasama, Japan. Am J Hypertens 1997; 10: 409-418.

19 Boggia J, Li Y, Thijs L, Hansen TW, Kikuya M, Bjorklund-Bodegard K, Richart T, Ohkubo T, Kuznetsova T, Torp-Pedersen C, Lind L, Ibsen H, Imai Y, Wang J, Sandoya E, O'Brien E, Staessen JA. International Database on Ambulatory blood pressure monitoring in relation to cardiovascular outcomes. Prognostic accuracy of day versus night ambulatory blood pressure: a cohort study. Lancet 2007; 370: 1219-1229.

20 Kikuya M, Hansen TW, Thijs L, Bjorklund-Bodegard K, Kuznetsova T, Ohkubo T, Richart T, Torp-Pedersen C, Lind L, Ibsen H, Imai Y, Staessen JA. International Database on Ambulatory blood pressure monitoring in relation to cardiovascular outcomes. Diag nostic thresholds for ambulatory blood pressure monitoring based on 10-year cardiovascular risk. Circulation 2007; 115: 2145-2152.

21 Thijs L, Staessen JA, Celis H, Fagard R, De Cort P, de Gaudemaris R, Enstrom I, Imai Y Julius S, Menard J, Mion D, Palatini P, Rosenfeld J, Shapiro D, Spence D, Stergiou G. The international database of self-recorded blood pressures in normotensive and untreated hypertensive subjects. Blood Press Monit 1999; 4: 77-86.

22 Schettini C, Bianchi M, Nieto F, Sandoya E, Senra H. Ambulatory blood pressure: normality and comparison with other measurements. Hypertension Working Group. Hypertension 1999; 34: 818-825.

23 Niu K, Hozawa A, Awata S, Guo H, Kuriyama S, Seki T, Ohmori-Matsuda K, Nakaya N Ebihara S, Wang Y, Tsuji I, Nagatomi R. Home blood pressure is associated with depressive symptoms in an elderly population aged 70 years and over: a populationbased, cross-sectional analysis. Hypertens Res 2008; 31: 409-416.

24 Nakagawa H, Niu K, Hozawa A, Ikeda Y, Kaiho Y, Ohmori-Matsuda K, Nakaya N, Kuriyama S, Ebihara S, Nagatomi R, Tsuji I, Arai Y. Impact of nocturia on bone fracture and mortality in older individuals: a Japanese longitudinal cohort study. J Urol 2010; 184: 1413-1418.

25 Mancia G, De Backer G, Dominiczak A, Cifkova R, Fagard R, Germano G, Grassi G, Heagerty AM, Kjeldsen SE, Laurent S, Narkiewicz K, Ruilope L, Rynkiewicz A, Schmieder RE, Boudier HA, Zanchetti A, Vahanian A, Camm J, De Caterina R, Dean V, Dickstein K, Filippatos G, Funck-Brentano C, Hellemans I, Kristensen SD, McGregor K, Sechtem U, Silber S, Tendera M, Widimsky P, Zamorano JL, Erdine S, Kiowski W, Agabiti-Rosei E, Ambrosioni E, Lindholm LH, Viigimaa M, Adamopoulos S, AgabitiRosei E, Ambrosioni E, Bertomeu V, Clement D, Erdine S, Farsang C, Gaita D, Lip G, Mallion JM, Manolis AJ, Nilsson PM, O'Brien E, Ponikowski P, Redon J, Ruschitzka F, Tamargo J, van Zwieten P, Waeber B, Williams B. 2007 Guidelines for the management of arterial hypertension: the task force for the management of arterial hypertension of the European Society of Hypertension (ESH) and of the European Society of Cardiology (ESC). J Hypertens 2007; 25 1105-1187.

26 O'Brien E, Pickering T, Asmar R, Myers M, Parati G, Staessen J, Mengden T, Imai Y, Waeber B, Palatini P, Gerin W. Working Group on Blood Pressure Monitoring of the European Society of Hypertension International Protocol for validation of blood pressure measuring devices in adults. Blood Press Monit 2002; 7: 3-17.

27 O'Brien E, Petrie J, Littler W, de Swiet M, Padfield P, Altman D, Bland M, Coats A Atkins N. The British Hypertension Society Protocol for the evaluation of blood pressure measuring devices. J Hypertens 1993; 11: S43-S63.

28 Association for the Advancement of Medical Instrumentation. The National Standard of Electronic or Automated Sphygmomanometers. Association for the Advancement of Medical Instrumentation, Arlington, 1987

29 Hesterberg T, Moore DS, Monaghan S, Clipson A, Epstein R. Bootstrap methods and permutation tests. In: Moore DS and McCabe G (eds) Introduction to the Practice of Statistics. WH Freeman \& Co, New York, 2005, pp 14-11-14-70.

30 NIPPON DATA80 Research Group. Risk assessment chart for death from cardiovascular disease based on a 19-year follow-up study of a Japanese representative population. Circ J 2006; 70: 1249-1255.

31 Wilson PW, D'Agostino RB, Levy D, Belanger AM, Silbershatz H, Kannel WB. Prediction of coronary heart disease using risk factor categories. Circulation 1998; 97 1837-1847.

32 Conroy RM, Pyorala K, Fitzgerald AP, Sans S, Menotti A, De Backer G, De Bacquer D, Ducimetiere P, Jousilahti P, Keil U, Njolstad I, Oganov RG, Thomsen T, Tunstall-Pedoe $H$, Tverdal A, Wedel H, Whincup P, Wilhelmsen L, Graham IMgroup Sp. Estimation of 
ten-year risk of fatal cardiovascular disease in Europe: the SCORE project. Eur Heart J 2003; 24: 987-1003.

33 dabl Educational Trust. Monitors for Self-Measurement of Blood Pressure. http:// www.dableducational.org/sphygmomanometers/devices_2_sbpm.html. Accessed 29 February 2012.

34 Imai Y, Nagai K, Sakuma M, Sakuma H, Nakatsuka H, Satoh H, Minami N, Munakata $\mathrm{M}$, Hashimoto J, Yamagishi T et al. Ambulatory blood pressure of adults in Ohasama, Japan. Hypertension 1993; 22: 900-912.

35 Yamashina A, Tomiyama H, Takeda K, Tsuda H, Arai T, Hirose K, Koji Y, Hori S, Yamamoto Y. Validity, reproducibility, and clinical significance of noninvasive brachialankle pulse wave velocity measurement. Hypertens Res 2002; 25: 359-364.

36 Imai Y, Abe K, Sasaki S, Minami N, Munakata M, Sakuma H, Hashimoto J, Sekino H, Imai K, Yoshinaga K. Clinical evaluation of semiautomatic and automatic devices for home blood pressure measurement: comparison between cuff-oscillometric and microphone methods. J Hypertens 1989; 7: 983-990.

37 Bortolotto LA, Henry O, Hanon O, Sikias P, Mourad JJ, Girerd X. Validation of two devices for self-measurement of blood pressure by elderly patients according to the revised British Hypertension Society protocol: the Omron HEM-722C and HEM-735C. Blood Press Monit 1999; 4: 21-25.

38 O'Brien E, Mee F, Atkins N, O'Malley K. Accuracy of the SpaceLabs 90207 determined by the British Hypertension Society protocol. J Hypertens 1991; 9: 573-574.

39 Thijs L, Hansen TW, Kikuya M, Bjorklund-Bodegard K, Li Y, Dolan E, Tikhonoff V, Seidlerova J, Kuznetsova T, Stolarz K, Bianchi M, Richart T, Casiglia E, Malyutina S, Filipovsky J, Kawecka-Jaszcz K, Nikitin Y, Ohkubo T, Sandoya E, Wang J, TorpPedersen C, Lind L, Ibsen H, Imai Y, Staessen JA, O'Brien E. Investigators I. The International Database of Ambulatory Blood Pressure in relation to Cardiovascular Outcome (IDACO): protocol and research perspectives. Blood Press Monit 2007; 12 : 255-262.

40 Staessen JA, Thijs L, Fagard R, O'Brien ET, Clement D, de Leeuw PW, Mancia G, Nachev C, Palatini P, Parati G, Tuomilehto J, Webster J. Predicting cardiovascular risk using conventional vs ambulatory blood pressure in older patients with systolic hypertension. Systolic Hypertension in Europe Trial Investigators. JAMA 1999; 282: 539-546.

41 Hanninen MR, Niiranen TJ, Puukka PJ, Johansson J, Jula AM. Prognostic significance of masked and white-coat hypertension in the general population: the Finn-Home Study. J Hypertens 2012; 30: 704-705.

42 Johansson JK, Niiranen TJ, Puukka PJ, Jula AM. Prognostic value of the variability in home-measured blood pressure and heart rate: the finn-home study. Hypertension 2012; 59: 212-218.

43 Kikuya M, Ohkubo T, Metoki H, Asayama K, Hara A, Obara T, Inoue R, Hoshi H, Hashimoto J, Totsune K, Satoh H, Imai Y. Day-by-day variability of blood pressure and heart rate at home as a novel predictor of prognosis: the Ohasama study. Hypertension 2008; 52: 1045-1050.

44 Pitsavos C, Panagiotakos DB, Chrysohoou C, Stefanadis C. Epidemiology of cardiovascular risk factors in Greece: aims, design and baseline characteristics of the ATTICA study. BMC Public Health 2003; 3: 32

\section{APPENDIX}

\section{IDHOCO Centers and Investigators}

Japan (Ohasama): K Asayama, T Ohkubo, M Kikuya, R Inoue, M Satoh, M Hosaka, MT Utsugi, T Hirose, A Hara, N Fukushima, T Obara, H Metoki, Y Imai; Finland (Finn-Home): T Niiranen, J Johansson, MR Hänninen, A Reunanen, A Jula; Japan (Tsurugaya): K Ohmori-Matsuda, S Kuriyama, M Kakizaki, A Hozawa, I Tsuji; Greece (Didima): G Stergiou; Uruguay (Montevideo): J Boggia, E Sandoya. 